\title{
Factors Related to the Utilization of Posyandu by Lansia in Campagaya Village in the UPTD Galesong Area Takalar District
}

\author{
Faktor-Faktor yang Berhubungan dengan Pemanfaatan Posyandu oleh Lansia \\ di Desa Campagaya di Wilayah UPTD Galesong Kabupaten Takalar
}

\author{
Fitriani, Nurekawati \\ STIKes Amanah \\ Jalan Hertasning Baru, Makassar \\ fitriani_muis@yahoo.co.id, ekha.nurekawati@gmail.com
}

\begin{abstract}
Posyandu for elderly people in a certain area that has been agreed upon, which is driven by the community where they can get health service. This study aims to determine the relationship between social support, attitudes and roles of cadres on the use of Posyandu in Campagaya Village in the working area of UPTD Galesong, Takalar Regency. The research design used an observational analytic design with a cross sectional approach. The population is all elderly in the village of Campagaya in the working area of UPTD Galesong, Takalar, amounting to 119 people. A total sample of 54 respondents who fall into the inclusion criteria. The independent variables are social support, attitudes and roles of cadres. The dependent variable is the use of Posyandu. Data were collected using a questionnaire and observation with a significance level of $<0.05$. The results showed that the relationship between social support for the elderly $(\rho=0.033)$, the relationship between family attitudes and the use of Posyandu $(\rho=0.001)$, the relationship between the role of cadres and the use of Posyandu $(\rho=0.000)$.
\end{abstract}

Keywords: social support, attitudes, role of cadres, use of posyandu

\begin{abstract}
Abstrak
Posyandu lansia di wilayah tertentu yang telah disepakati bersama, didorong oleh masyarakat untuk mendapatkan pelayanan kesehatan. Penelitian ini bertujuan untuk mengetahui hubungan dukungan sosial, sikap dan peran kader terhadap pemanfaatan Posyandu di Desa Campagaya Wilayah Kerja UPTD Galesong Kabupaten Takalar. Desain penelitian menggunakan desain analitik observasional dengan pendekatan cross sectional. Populasi adalah seluruh lansia di Desa Campagaya wilayah kerja UPTD Galesong Kabupaten Takalar yang berjumlah 119 orang. Jumlah sampel sebanyak 54 responden yang masuk dalam kriteria inklusi. Variabel bebasnya adalah dukungan sosial, sikap dan peran kader. Variabel terikat adalah pemanfaatan posyandu. Pengumpulan data dilakukan dengan menggunakan kuesioner dan observasi dengan tingkat signifikansi $<0,05$. Hasil penelitian menunjukkan bahwa ada hubungan antara dukungan sosial terhadap lansia $(\rho=0,033)$.
\end{abstract}

Kata kunci: dukungan sosial, sikap, peran kader, pemanfaatan posyandu

\section{PENDAHULUAN}

Data yang diperoleh berdasarkan sensus penduduk pada tahun 2012 di mana jumlah penduduk Indonesia yang tergolong usia 60 tahun ke atas adalah 19 juta dengan persentase 8,5\% dari total jumlah penduduk. dan terjadi peningkatan 3-4 juta penduduk lansia tiap dekade berikutnya ( Cahyaningtyas, 2012). Hal ini berkaitan dengan kesehatan pada lansia dan sebaiknya lebih diperhatikan di mana kondisi fisik dan fungsi organ tubuh lansia sudah tidak sesempurna seperti ketika masih muda.( Hardywinoto, 2015)

Lansia yang jarang mengunjungi layanan kesehatan di posyandu lansia, maka dapat menyebabkan untuk sulit memantau kondisi kesehatan mereka dengan baik, sehingga ketika lansia mengalami suatu gangguan kesehatan akibat terjadinya penurunan kondisi tubuh dikhawatirkan akan berakibat fatal dan dapat mengancam jiwa mereka. sosialisasi dan penyuluhan mengenai manfaat posyandu lansia perlu ditingkatkan dan dilakukan sosialisasi kepada masyarakat untuk

\footnotetext{
The Maternal \& Neonatal Health Journal is an open-access journal published by Neolectura, published twice a year. Maternal \& Neonata Health Journal is a scientific publication media in the form of conceptual papers and field research related to the study of obstetrics, reproductive health, infants, toddlers, and development. The Maternal \& Neonatal Health Journal is expected to be a medium for researchers and researchers to publish scientific work and become a reference source for developing science and knowledge.
} 
mendapatkan dukungan dari berbagai pihak, yakni keluarga, pemerintah maupun masyarakat itu sendiri.( Handoko, M. 2008)

Berdasarkan data yang diperoleh kader mengatakan ketidakhadirannya lansia ke posyandu dikarenakan kondisi fisik yang terjadi pada lansia seperti sedang sakit, tidak adanya anggota keluarga yang mengantarkan ke posyandu, sehingga mengakibatkan lansia yang datang ke posyandu dapat dikatakan sedikit tiap bulannya, meskipun dari keterangan kader posyandu sebenarnya sikap lansia terhadap posyandu adalah baik, di mana ada keinginan lansia yang berkunjung ke posyandu sesuai dengan jadwal pelayanan posyandu.

Berdasarkan latar belakang maka peneliti ingin mengetahui faktor apa saja yang berhubungan dengan penggunaan posyandu oleh lansia di Desa Campagaya Wilayah UPTD Galesong Kabupaten Takalar.

\section{METODE}

Jenis penelitian adalah observasional dengan pendekatan cross sectional tujuannya untuk mengetahui hubungan antara variabel dan menguji hipotesis yang dirumuskan dan melakukan pengukuran variabel dependen dan independen hanya sekali tanpa melakukan follow up.

\section{HASIL DAN PEMBAHASAN}

\section{Hasil}

Tabel 1. Hubungan Dukungan Sosial dengan Penggunaan Posyandu Lansia di Desa Campagaya Wilayah UPTD Galesong.

\begin{tabular}{lccccc}
\hline \multirow{2}{*}{$\begin{array}{c}\text { Dukungan } \\
\text { Sosial }\end{array}$} & \multicolumn{5}{c}{ Penggunaan Posyandu } \\
\cline { 2 - 5 } & Aktif & $\%$ & Tidak Aktif & $\%$ & $P$ \\
\hline Baik & 7 & 13.0 & 6 & 11,1 & 13 \\
\hline Cukup & 10 & 18.5 & 29 & 53.7 & 39 \\
\hline Kurang & 0 & 0,0 & 2 & 1,4 & 2 \\
\hline Total & 17 & 31.5 & 37 & 66.2 & 54 \\
\hline Sumber: Diolah (2020) & & & & &
\end{tabular}

Tabel 2. Hubungan Sikap dengan Penggunaan Posyandu Lansia di Desa Campagaya Wilayah UPTD Galesong.

\begin{tabular}{llccccc}
\hline \multirow{2}{*}{ Sikap } & \multicolumn{5}{c}{ Penggunaan Posyandu } \\
\cline { 2 - 6 } & Aktif & $\%$ & Tidak Aktif & $\%$ & \multirow{2}{*}{ Total } \\
& 10 & 18.5 & 5 & 9.3 & 15 & \multirow{2}{*}{0,001} \\
\hline Positif & 7 & 13.0 & 32 & 59.3 & 39 & \\
\hline Negatif & 17 & 31.5 & 37 & 68.6 & 54 & \\
\hline Total & Sumber: Diolah (2020) & & & & &
\end{tabular}

Tabel 3. Hubungan Peran Kader dengan Penggunaan Posyandu Lansia di Desa Campagaya Wilayah UPTD Galesong

\begin{tabular}{ccccccc}
\hline \multirow{2}{*}{$\begin{array}{c}\text { Dukungan } \\
\text { Sosial }\end{array}$} & \multicolumn{5}{c}{ Tenggunaan Posyandu } & $P$ \\
\cline { 2 - 6 } & Aktif & $\%$ & Tidak Aktif & $\%$ & & \\
\hline Baik & 17 & 31.5 & 1 & 1.9 & 18 & 0,000 \\
\hline
\end{tabular}




\title{
in Campagaya Village in the UPTD Galesong Area Takalar District
}

\author{
Fitriani, Nurekawati
}

STIKes Amanah

\begin{tabular}{llllll} 
Cukup & 0 & 0.0 & 33 & 61.1 & 33 \\
\hline Kurang & 0 & 0.0 & 3 & 2.1 & 3 \\
\hline Total & 17 & 31.5 & 37 & 65.1 & 54 \\
\hline
\end{tabular}

Sumber: Diolah (2020)

\section{Pembahasan}

Berdasarkan hasil penelitian menunjukkan bahwa distribusi frekuensi berdasarkan dukungan sosial dengan penggunaan posyandu lansia di Desa Campagaya Wilayah UPTD Galesong, terdapat 13 orang dengan memiliki dukungan sosial yang baik dengan aktif memanfaatkan keberadaan Posyandu sebanyak 7 orang (13.0\%) dan 6 orang (11.1\%) tidak aktif memanfaatkan pelayanan Posyandu dan 39 lansia yang memiliki dukungan yang cukup 10 orang (18.5\%) aktif datang memanfaatkan Posyandu dan 29 orang (53.7\%) tidak aktif memanfaatkan Posyandu. Berdasarkan hasil uji statistik spearman correllation didapatkan nilai $\rho=0.033(\alpha<0,05)$. Maka dapat disimpulkan bahwa ada hubungan antara dukungan sosial dengan pemanfaatan Posyandu lansia.

Sesuai dengan teori Cahyaningtyas, mengatakan bahwa dukungan sosial yang bersifat menolong dan mempunyai nilai khusus bagi individu yang menerimanya dan orang yang dipercaya dapat membantu, menghargai serta mencintai ketika seseorang menghadapi masalah sehingga individu tersebut mengetahui bahwa orang lain memperhatikan, menghargai dan mencintai dirinya. merupakan ikatan sosial (Mangoenprasodjo A, 2005).

Maka dapat disimpulkan bahwa dukungan sosial terhadap lansia sangat penting karena akan membuat lansia termotivasi dalam memelihara kesehatan demi kesejahteraan. Dukungan yang baik dari keluarga dan lingkungan sangat diharapkan bagi lansia agar lansia dapat memperoleh informasi, sarana dan prasarana serta dukungan moril guna menunjang kualitas hidup lansia tersebut.

Dari hasil penelitian juga diperoleh bahwa sikap responden dengan penggunaan posyandu lansia adalah 15 orang yang mempunyai sikap yang positif dengan 10 orang (18.5\%) lansia aktif memanfaatkan posyandu dan 5 orang $(9.3 \%)$ tidak aktif memanfaatkan posyandu. Sedangkan lansia yang memiliki sikap negatif sebanyak 39 lansia dengan 7 orang (13.0) aktif memanfaatkan posyandu dan 32 lansia (59.3\%) tidak aktif memanfaatkan posyandu. Berdasarkan uji statistik chi square dengan metode fisher's exact test diperoleh nilai $\rho=0.001(\alpha<0,05)$, yang berarti ada hubungan bermakna antara sikap dengan pemanfaatan posyandu lansia.

Sikap dapat bersifat positif dan dapat bersifat negatif, pada sikap positif cenderung tindakan adalah mendekati, menyenangi, mengharapkan objek tertentu sedangkan pada sikap negatif terdapat kecenderungan untuk menjauhi, menghindar, membenci dan tidak menyukai objek tertentu (Niven, N. 2009).

Maka dapat disimpulkan bahwa sikap lansia dapat mempengaruhi lansia dalam memanfaatkan posyandu lansia karena lansia cenderung tidak melaksanakan perilaku yang baik yaitu dengan tidak rajin memantau kesehatannya ke posyandu. Untuk meningkatkan kesadaran lansia maka perlu diadakan berbagai penyuluhan baik penyuluhan secara langsung maupun tidak langsung mengenai manfaat posyandu bagi lansia.

Hasil penelitian juga memperoleh bahwa peran kader terhadap responden dengan penggunaan posyandu lansia terdapat 18 orang kader yang mempunyai peran yang baik terhadap pemanfaatan posyandu lansia dengan 17 orang (31.5\%) memanfaatkan posyandu secara baik dan 1 orang $(1.9 \%)$ yang memanfaatkan posyandu secara cukup. Sedangkan terdapat 36 orang (66.6\%) kader yang mempunyai peran yang cukup terhadap pemanfaatan posyandu bagi lansia dengan 0 orang $(0.0 \%)$ dan tidak menggunakan posyandu secara baik dan 36 orang(66.6\%) memanfaatkan posyandu secara cukup. Dari hasil uji statistik chi square dengan metode pearson chis square didapatkan nilai $\rho=0.000,(\alpha<0,05)$, terdapat hubungan peran kader dengan pemanfaatan posyandu lansia.

Maka disimpulkan peran kader sangat menentukan keaktifan lansia untuk datang ke posyandu karena dengan informasi-informasi yang diberikan sehingga lansia dapat lebih memahami manfaat posyandu lansia. Dengan demikian diharapkan agar kader kesehatan lebih aktif lagi dalam memberikan penyuluhan-penyuluhan terhadap lansia tentang cara mengenali dan mengatasi masalah kesehatan. 


\section{PENUTUP}

Berdasarkan hasil penelitian menunjukkan terdapat hubungan yang signifikan antara dukungan sosial dengan penggunaan posyandu lansia di Desa Campagaya Wilayah UPTD Galesong dengan nilai $\rho=0.033(\alpha<0,05)$, terdapat hubungan antara sikap lansia terhadap pemanfaatan posyandu lansia di Desa Campagaya Wilayah UPTD Galesong, di mana $\rho=0.001(\alpha<0,05)$, dan terdapat hubungan antara peran kader terhadap penggunaan posyandu lansia di Desa Campagaya Wilayah UPTD Galesong, di mana $\rho=0.000(\alpha<0,05)$.

Diharapkan kepada para lanjut usia untuk lebih aktif dalam kegiatan di posyandu lansia serta Diharapkan posyandu lanjut usia lebih memperhatikan faktor yang dapat meningkatkan keaktifan dan minat lanjut usia untuk menggunakan fasilitas posyandu yang disediakan.

\section{DAFTAR PUSTAKA}

Cahyaningtyas, N. (2012). Hubungan Antara Dukungan Sosial dengan Motif Berprestasi Anak Underchielen. Surakarta: Fakultas Psikologi UMS.

Hardywinoto. (2015). Panduan Gerontologi Tinjauan Dari Berbagai Aspek. Jakarta:

PT.Cetakan kedua. Gramedia Puataka Utama.

Handoko, M. (2008). Motivasi Daya Penggerak Tingkah Laku, Yogyakarta: Penerbit Kanisius.

Johnson, D.W. (2011). Joining Together Group Theory and Group Skills 4th edition. New Jersey: Prentice Hall.

Mangoenprasodjo A. (2005). Mengisi Hari Tua Dengan bahagia. Yogyakarta: Gramedia Puataka Utama

Niven, N. (2009). Psokologi Kesehatan Pengantar untuk Perawat Profesional Kesehatan Lain Edisi 2. Jakarta: EGC

Notoadmojo. (2005). Pendidikan dan Perilaku Kesehatan. Rineka cipta: Jakarta

Notoatmodjo, S. (2007). Metodologi Penelitian Kesehatan. Jakarta: PT Rineka Cipta.

Nugroho, (2000). Keperawatan Gerontik. Edisi 2 Penerbit buku Kedokteran. Jakarta: EGC. Pudjiastuti. (2003). Fisioterapi Pada Lansia. EGC: Jakarta.

Sarafino, E.P. (2004). Health Psychology. Biopsychosocial Interactions. New York: John Willey \& Sons, Inc

Sugiyono. (2005). Statistika Untuk Penelitian. Bandung: Alfabeta.

Sukarni M. (2018). Kesehatan Keluarga Dan Lingkungan. Yogyakarta: Kanisius

Walgito, B. (2007). Psikologi Sosial (Suatu Pengantar) Edisi 3. Yogyakarta: Andi Offset

Watson, (2003). Perawatan pada Lansia. Jakarta: EGC. 